\title{
Oldest ctenodactyloid tarsals from the Eocene of China and evolution of locomotor adaptations in early rodents
}

\author{
Łucja Fostowicz-Frelik, ${ }^{1,2^{*}}$, Qian $\mathrm{Li}^{1}$ and Xijun $\mathrm{Ni}^{1}$
}

\begin{abstract}
Background: Tamquammys has been considered one of the basal ctenodactyloid rodents, which has been documented in the earliest to middle Eocene ( 56.0-48.5 Ma) in China. It was the most abundant and widespread rodent genus in the Erlian Basin (Nei Mongol, China) and dominated Arshantan small-mammal faunas of that region. Here for the first time we describe the morphology of the astragalocalcaneal complex in Tamquammys robustus (larger) and T. wilsoni, and interpret it against the background of locomotor adaptations of basal Euarchontoglires (rodents, lagomorphs, tree shrews, and primates).

Results: The comparative morphology of the tarsal elements in Tamquammys robustus and T. wilsoni shows overall slenderness of the bones and their similarity to the tarsal elements of Rattus, a generalist species, and those of small rock squirrels (e.g. Sciurotamias). The two species differ slightly in their cursorial ability; smaller T. wilsoni shows some adaptations to climbing. The results of principal component analysis of the calcaneus and astragalus support this observation and place T. robustus in-between Rattus and ground/rock squirrel morphospace, and T. wilsoni closer to euarchontans, Tupaia and Purgatorius.

Conclusions: The morphology of the tarsal elements in Tamquammys indicates a generalist rodent morphotype with no particular adaptations to arboreality. We suggest that Tamquammys as a basal ctenodactyloid is closer to the ancestral astragalocalcaneal morphology of rodents than that of more derived North American paramyines of similar age. Overall similarity in Tamquammys tarsal elements structure to Purgatorius, a basal primate, may point to the antiquity of the tarsal structure in Tamquammys and a generally unspecialized foot structure in early Euarchontoglires.
\end{abstract}

Keywords: Glires, Rodentia, Paleogene, Asia, Foot structure, Locomotion, Morphological evolution

\section{Background}

Tamquammys is one of the earliest ctenodactyloid rodents known from the early Eocene of Asia [1]. Its remains have been reported from the Eocene deposits of the Zaysan Basin in Kazakhstan [1], the Erlian Basin in Nei Mongol (NE China) [2-4], and the Hetaoyuan Formation, Henan Province in the central China [5]. The earliest species of Tamquammys were coeval with the early Eocene rodents Advenimus, Chenomys, Cocomys,

\footnotetext{
* Correspondence: Ifost@twarda.pan.pl

'Key Laboratory of Vertebrate Evolution and Human Origins, Institute of Vertebrate Paleontology and Paleoanthropology, Chinese Academy of Sciences, 100044 Beijing, People's Republic of China

${ }^{2}$ Institute of Paleobiology, Polish Academy of Sciences, 00-818 Warszawa, PL, Poland
}

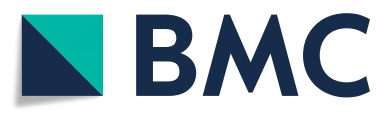

(๑) The Author(s). 2018 Open Access This article is distributed under the terms of the Creative Commons Attribution 4.0 International License (http://creativecommons.org/licenses/by/4.0/), which permits unrestricted use, distribution, and

reproduction in any medium, provided you give appropriate credit to the original author(s) and the source, provide a link to the Creative Commons license, and indicate if changes were made. The Creative Commons Public Domain Dedication waiver (http://creativecommons.org/publicdomain/zero/1.0/) applies to the data made available in this article, unless otherwise stated.

and Yuanomys $[3,4])$, and are preceded in the fossil record by basal simplicidentates, namely Alagomyidae (including Tribosphenomys) and Eurymylidae [6, 7]. Tamquammys was a relatively long-lasting genus, which survived into the Middle Eocene, matched in this respect only by Advenimus [4].

Tamquammys was most abundant and diversified in the Erlian Basin, Nei Mongol, where its earliest, although scarce, remains were found, from the upper part of the Nomogen Formation (NS-3), representing the Bumbanian Asian Land-Mammal Age [3, 8, 9]. During the next ALMA, Arshantan, Tamquammys became a dominant and, for most of this interval, the only rodent genus in the early Eocene ecosystems of Nei Mongol [4]. Several thousand of specimens (teeth, skull 
fragments, and postcranial elements) assigned to this genus have been recovered from early-to-middle Eocene fossil beds by screen-washing and surface collecting [3, 4].

Four species of Tamquammys have been recognized in the Nei Mongol deposits thus far; Tamquammys wilsoni (Fig. 1b, c) was the most abundant and persistent in the fossil record, ranging from the earliest Eocene (Bumbanian) to the early middle Eocene (Irdinmanhan) [3]. Tamquammys robustus (Fig. 1a, d), the largest and earliest species of the genus, is known from the early Bumbanian to early Arshantan only. In the earliest Arshantan it coexisted with $T$. longus, which is not known during the Irdinmanhan. In the early middle Eocene (Irdinmanhan) another species, $T$. fractus, coexisted with $T$. wilsoni, both being relatively small.

The astragalus and calcaneus are the largest of the ankle bones (tarsals) and form the lower ankle joint, while contributing to the upper ankle joint (the astragalus) and transverse tarsal joint (both bones). The significance of these bones for paleobiology stems from the fact that they are very commonly preserved in the fossil record, second in this respect only to the teeth. The tarsal bones, as a functional unit, are in direct contact with the substrate and thus are immediately related to an animal's lifestyle [10-12]. Their morphology provides information on the locomotor adaptations of fossil representatives which are otherwise known very incompletely $[13,14]$. However, the tarsals of the Eocene Glires have been subject of detailed studies very rarely [15-17].

This paper focuses on the tarsal bones morphology of the two most abundant species of Tamquammys in Nei Mongol: T. robustus and T. wilsoni (Fig. 1). We compared the bone morphology of Tamquammys with that of several genera of Euarchontoglires of known locomotor adaptations in order to establish probable habits of this early rodent. Given that in the recent phylogenies ctenodactyloids are nested below ischyromyid (including paramyine) rodents (Fig. 2), we propose that the former would represent a more basal morphotype than the latter. Our study aims at the reconstruction of supposed locomotor adaptations and lifestyle inference of Tamquammys and consequently the probable ancestral

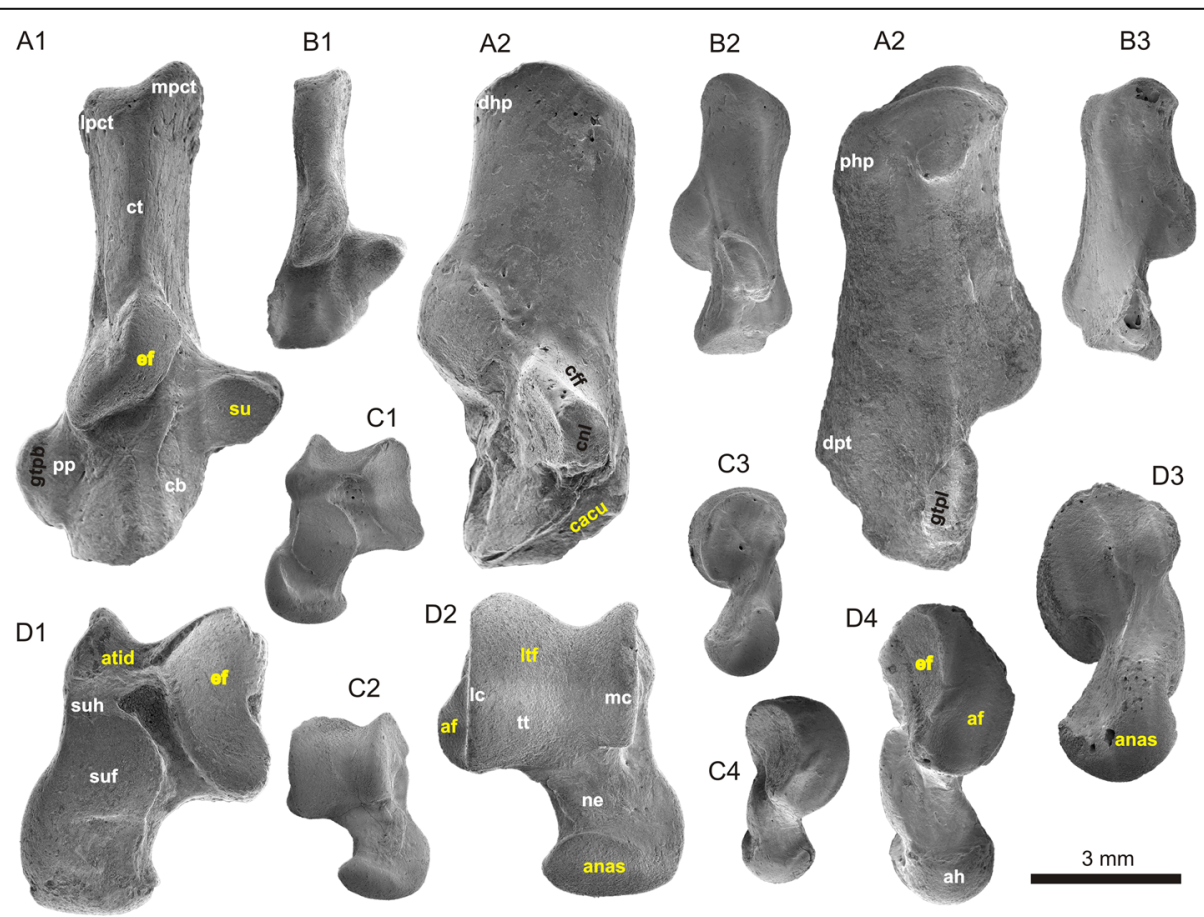

Fig. 1 Morphology of calcaneus (a, b) and astragalus (c, d) in Tamquammys robustus (A, C; IVPP V24136.1 and V24136.4 respectively) and Tamquammys wilsoni (B, D, IVPP V V24137.2 and V24137.4 respectively; mirror images) from Nuhetingboerhe, Nei Mongol, China. Bones shown in dorsal (A1, B1, C2, D2), medial (A2, B2, C3, D3), lateral (A3, B3, C4, D4), and plantar (D1, C1) views. Abbreviations (yellow denotes articular surfaces, white other major anatomical structures, and black, grooves for major tendons): af, astragalofibular articulation surface; ah, astragalar head; anas, astragalonavicular articulation surface; atid, distal astragalotibial articulation surface (aff, astragalar groove for tendon of flexor fibularis muscle sensu Chester et al. 2015); cacu, calcaneocuboid articulation facet; cb, calcaneal body; cff, calcaneal groove for tendon of flexor fibularis muscle; $\mathrm{cnl}$, calcaneonavicular ligament; ct, calcaneal tuber; dhp, dorsal heel process; dpt, distal plantar tubercle; ef, ectal facet (on both calcaneus and astragalus); gtpb, grove for tendon of peroneus brevis muscle; gtpl, grove for tendon of peroneus longus muscle; Ic, lateral astragalar crest; Ipct, lateral process of calcaneal tuber; Itf, lateral tibial facet; mc, medial crest of astragalar trochlea; mpct, medial process of calcaneal tuber; ne, astragalar neck; php, plantar heel process; pp., peroneal process; su, sustentaculum tali with sustentaculum facet; suf, sustentacular facet of astragalus; suh, sustentacular hinge; tt, trochlea tali 


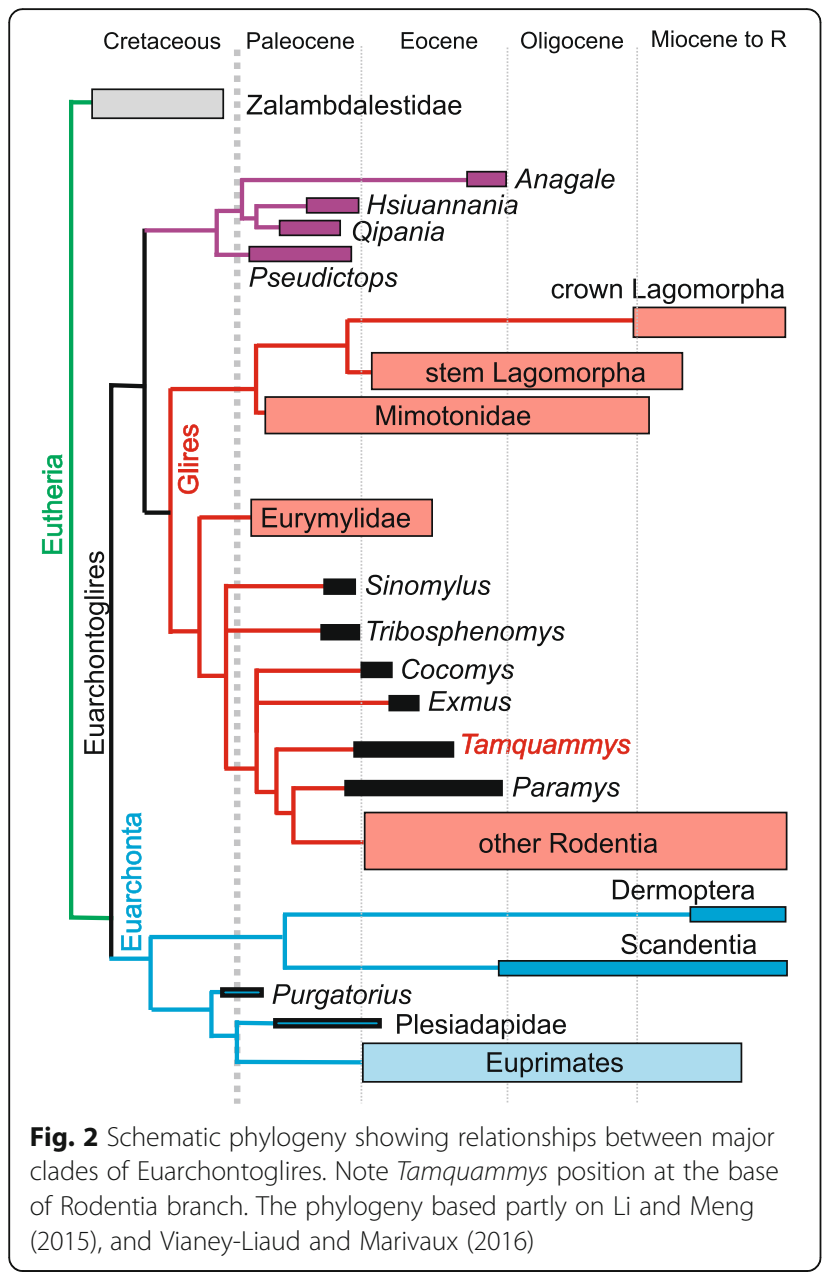

morphotype for early rodents. We argue that the putative 'protorodent' of Szalay [15] would be rather a generalist than arboreal (scansorial).

\section{Results}

\section{Comparative morphology of the astragalocalcaneal complex in Tamquammys \\ Calcaneus}

The calcaneus of Tamquammys is relatively slender (Figs. 1 and 3, Additional file 1: Figure S2A), similarly to that of some ground squirrels (Marmota in particular), Rattus (Fig. 3), and Mus, indicating the overall locomotor dexterity of an animal. The calcaneus of Tamquammys is straight, without bending observed in some arboreal rodents (e.g., Glis, Sciurus see Fig. 4, or Ratufa, [12]: fig. 3d; [18]: figs. 12-13), primates (e.g., Proteopithecus or Callicebus; [19]: figs. 1-3, 12, 13) or to a lesser extent in ground and rock squirrels (e.g., Cynomys and Sciurotamias, respectively; Fig. 3).

The calcaneal body is moderately elongated (Additional file 1: Figure S2B), which generally reflects aptness to bounding, jumping and swift running [10, 12], and the elongation is greater than that in paramyines (see [17]), Gomphos, basal primates (Purgatorius), and Tupaia, but lesser than in squirrels and the small lagomorph Ochotona. The calcaneal load arm is very similar in both species of Tamquammys extending between that of Rattus, Cricetus, and Marmota, but closer to the rat (Additional file 1: Figure S2B).

The sustentaculum tali is relatively large (almost as large as in Tribosphenomys, which shows the largest sustentaculum among the studied taxa), roundish in outline and slightly pointed medially, less so than in Rattus (Figs. 1 and 3). A large articular surface of the sustentaculum allows for a greater freedom of movement along the astragalocalcaneal juncture in many planes, other than the parasagittal one [12]. The sustentaculum is anteroposteriorly longer than in Rattus, similar to that of Marmota but wider mediolaterally. The sustentaculum forms an approximately right angle with the calcaneal tuber, and is not inclined anteriorly as in Cynomys, Glis, Sciurotamias, and Sciurus. It is placed relatively posteriorly to the calcaneal eminence which bears the ectal facet (Figs. 1 and 3), and its posterior margin is aligned with the mid-length of the ectal facet, similar to Purgatorius (see [20]: fig. 1) and Tribosphenomys, and only slightly more anterior than in Gomphos (and other duplicidentates, showing most posteriorly shifted sustentacula, see e.g., Ochotona: Fig. 4d). This is a more posterior position of the sustentacular facet (in relation to the ectal facet) than that in ground and rock squirrels (especially Cynomys and Sciurotamias), paramyines, and Tupaia (see also Fig. 5). The medial edge of the sustentaculum bears a well-shaped groove (Fig. 1) for the calcaneonavicular ligament [21].

In two of the three specimens of Tamquammys robustus and in two of five of T. wilsoni there is a minute foramen in the calcaneal body at the base of the sustentaculum tali, which may or may not be homologous with the anterior opening of the calcaneal canal in Lagomorpha (sensu Bleefeld and Bock [22]; see also Zhang et al. [23]).

The calcaneal eminence in Tamquammys bearing the ectal facet is relatively long (Additional file 1: Figure S2D) and not strongly curved (Fig. 3), again indicating some greater mobility at this surface, especially in the smaller species (T. wilsoni). The ectal facet is also somewhat helical (sensu Rose and Chinnery [17]), which suggests improved capability of foot inversion and eversion in Tamquammys.

The peroneal process is located in the mid-length of the calcaneal body in $T$. robustus and shifted slightly more posteriorly in T. wilsoni (Figs. 1 and 3), and provides a leverage for the tendon of the peroneus longus muscle (running along the lateral surface of the process in a sinusoidal groove, Fig. 1). In Tamquammys 


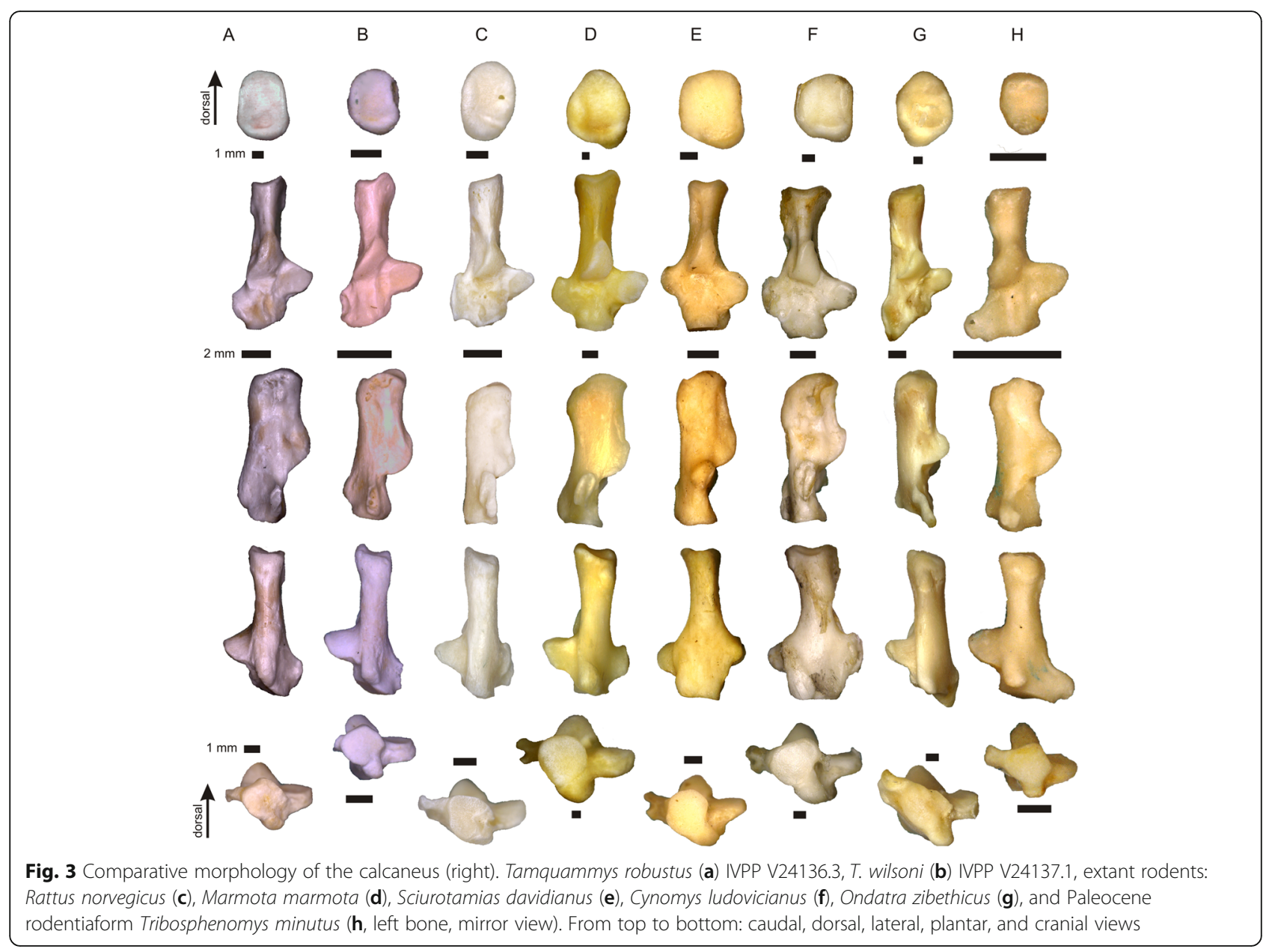

it is a distinct flattened tubercle, somewhat round at its lateral rim, less extended anteroposteriorly than that in Rattus, Glis, and smaller than in squirrels such as Cynomys or Sciurus (Fig. 3), as well as Purgatorius ([20]: fig. 1), where it forms a petal-like extension at the calcaneal body. On the other hand, the peroneal tubercle in Tamquammys is larger, more flat and shifted more anteriorly than the peroneal tubercle in Sciurotamias and other ground squirrels (Fig. 3). The shape of the peroneal tubercle in Tamquammys resembles more closely that of paramyines; in T. wilsoni it is slightly closer to the calcaneocuboid surface than in $T$. robustus.

The anterior plantar tubercle is distinct in Tamquammys (better developed than in Rattus), forming a round knob at the plantar surface of the bone, roughly in the sagittal plane of the bone (not shifted medially as in some ground squirrels, Fig. 3e, f). It is located quite far from the edge of the calcaneocuboid surface (but relatively closer than in Duplicidentata; [24, 25]). In both species of Tamquammys the plantar surface of the calcaneus between the anterior plantar tubercle and the plantar heel process is gently concave, similar to that of ground squirrels (especially Marmota) and Tribosphenomys (Fig. 3).
The calcaneal tuber in Tamquammys is moderately long and slender, compressed mediolaterally and high dorsoplantarly (Figs. 1 and 3). The caudal surface of the tuber, forming the insertion for the Achilles tendon is regularly oval in T. wilsoni and rectangular in T. robustus (Fig. 3). The groove marking the tendon attachment is oriented mediolaterally, indicating the pull of the calcaneal tendon exerted strictly in the parasagittal plane. The shape of the caudal surface of the tuber resembles that of Rattus, but is more rectangular and generally more compressed mediolaterally than in all ground squirrels, and much more than in Gomphos, which shows a very strong compression of the tuber in the opposite, dorsoplantar direction (Fig. 5).

The medial and lateral tubercles at the calcaneal tuber, which form attachments for the superficial digitor flexors, are well developed and extend strictly in the caudal direction, not flaring mediolaterally as much as in ground squirrels. This supports the observation that the action of these tendons, flexion of the toes, is exerted in parasagittal plane, thus the toes are grasping, but without spreading out very much. 


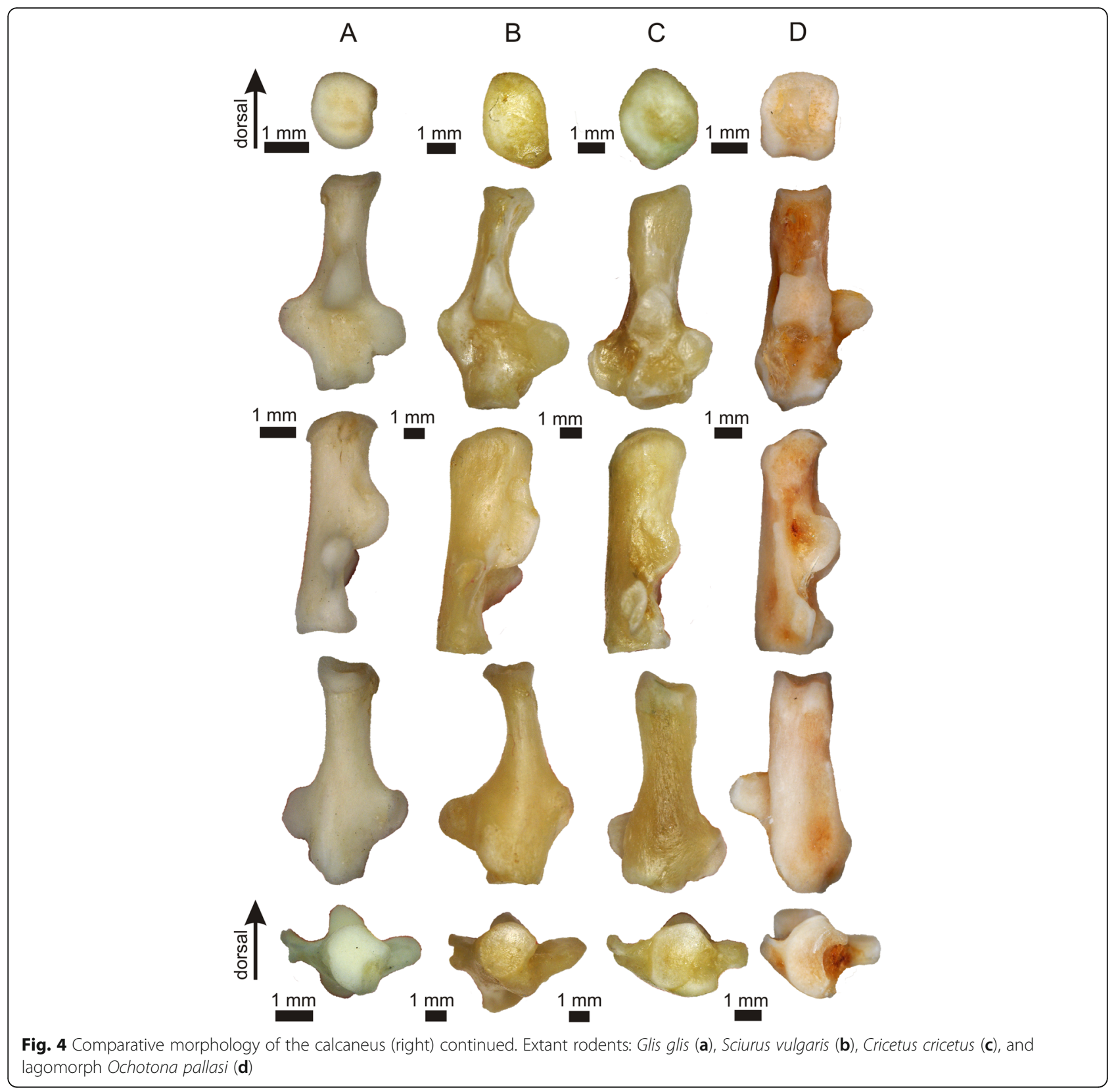

The plantar side of the calcaneal tuber bears a moderately shaped plantar heel process for the origin of flexor digitorum brevis muscle (Fig. 1; [12]: fig. 1a), which is weaker and more terminally located than in ground and rock squirrels, but better developed than in Rattus and Ondatra. The dorsal side of the tuber in Tamquammys is not 'pinched' as in typical arboreal taxa (e.g., Sciurus, see Fig. 4b, also Rose and Chinnery [17]: fig. 13) and the pit for the calcaneofibular ligament is relatively shallow and placed close to the calcaneal eminence, suggesting that a weak ligament binding rendered the joint relatively flexible.
The calcaneocuboid surface is relatively isometric (Fig. 3, Additional file 1: Figure S2E), roundish to semicircular. The intrageneric difference is slight, but indicates a greater freedom of movement along the calcaneocuboid facet (in mediolateral direction) in T. wilsoni, which supports somewhat more developed climbing ability in this species in comparison with $T$. robustus. Furthermore, the surface of the calcaneocuboid facet is inclined ca. $30-40^{\circ}$ to the longitudinal plane, which is typical of terrestrial taxa $[15,20]$. Such an inclination of the calcaneocuboid surface actually prevents extensive inversion and eversion of the foot. The inclination of the 

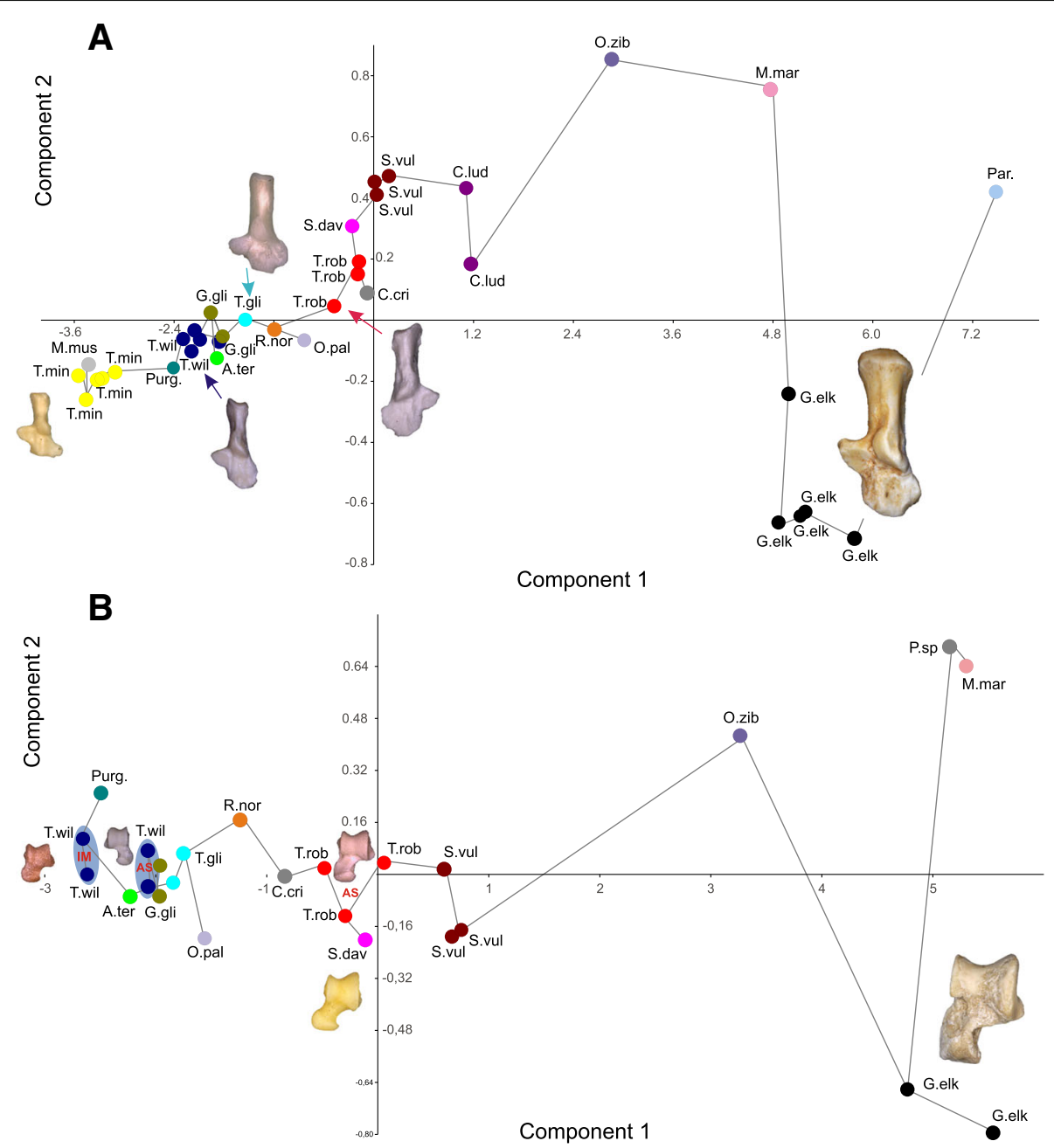

Fig. 5 Results of principal component analysis of 15 calcaneal (a) and 12 astragalar (b) measurements for 19 species. A set of lines connecting all data points represents a minimum spanning tree based on a Euclidean distance matrix. Results support Tamquammys robustus as an agile terrestrial ecomorph and T. wilsoni as a non-specialized occasionally arboreal species. Species abbreviations: A.te, Arvicola terrestris; C.cr, Cricetus cricetus; C.lu, Cynomys ludovicianus; G.el, Gomphos elkema; G.gl, Glis glis; M.ma, Marmota marmota; M.mu, Mus musculus; O.pa, Ochotona pallasi; O.zi, Ondatra zibethicus; Par., paramyid; P.sp., Paramys sp.; Pur., Purgatorius; R.no, Rattus norvegicus; S.da, Sciurotamias davidianus; S.vu, Sciurus vulgaris; T.gl, Tupaia glis; T.mi, Tribosphenomys minutus; T.ro, Tamquammys robustus; T.wi, Tamquammys wilsoni. AS, Arshantan ALMA; IM, Irdinmanhan ALMA

calcaneocuboid surface in Tamquammys is stronger than in all studied rodents, including paramyines [17]. The inclined astragalocalcaneal surface is present in Tribosphenomys (Fig. 3), Protungulatum, Procerberus, Plesiadapis [21], and Purgatorius [20], although the inclination is less marked than that in Tamquammys. On the other hand, the stronger inclination is found in all duplicidentates (e.g., in Gomphos, Mimolagus, and lagomorphs (Fig. 4d); [26, 27]), which are cursorial.

\section{Astragalus}

The astragalus of both species of Tamquammys is relatively slender with an elongated neck corresponding to a relatively elongated body of the calcaneus (Fig. 6, Additional file 1: Figure S3A and B). The elongation of the neck is lesser than in Sciurotamias, similar to that of Paramys sp. [17] and Tupaia, but larger than in Rattus, Marmota, and Purgatorius (Fig. 3, Additional file 1: Figure S3B).

The trochlea is deep and slightly asymmetric, deeper than in Rattus, Ondatra (Fig. 6), primates, and Tupaia, with the well-defined and high ridges, which are, however, lower than those of Glis. The trochlear area of the lateral tibial facet (ltf sensu Chester et al. [20]) and especially the distal astragalotibial surface [15] (astragalar groove for the tendon of the flexor fibularis muscle sensu Chester et al. [20]) are extended anteroposteriorly, suggesting a considerable anteroposterior freedom of movement in the crural joint. On the other hand, the lateral tibial facet at the trochlea does not extend at the 


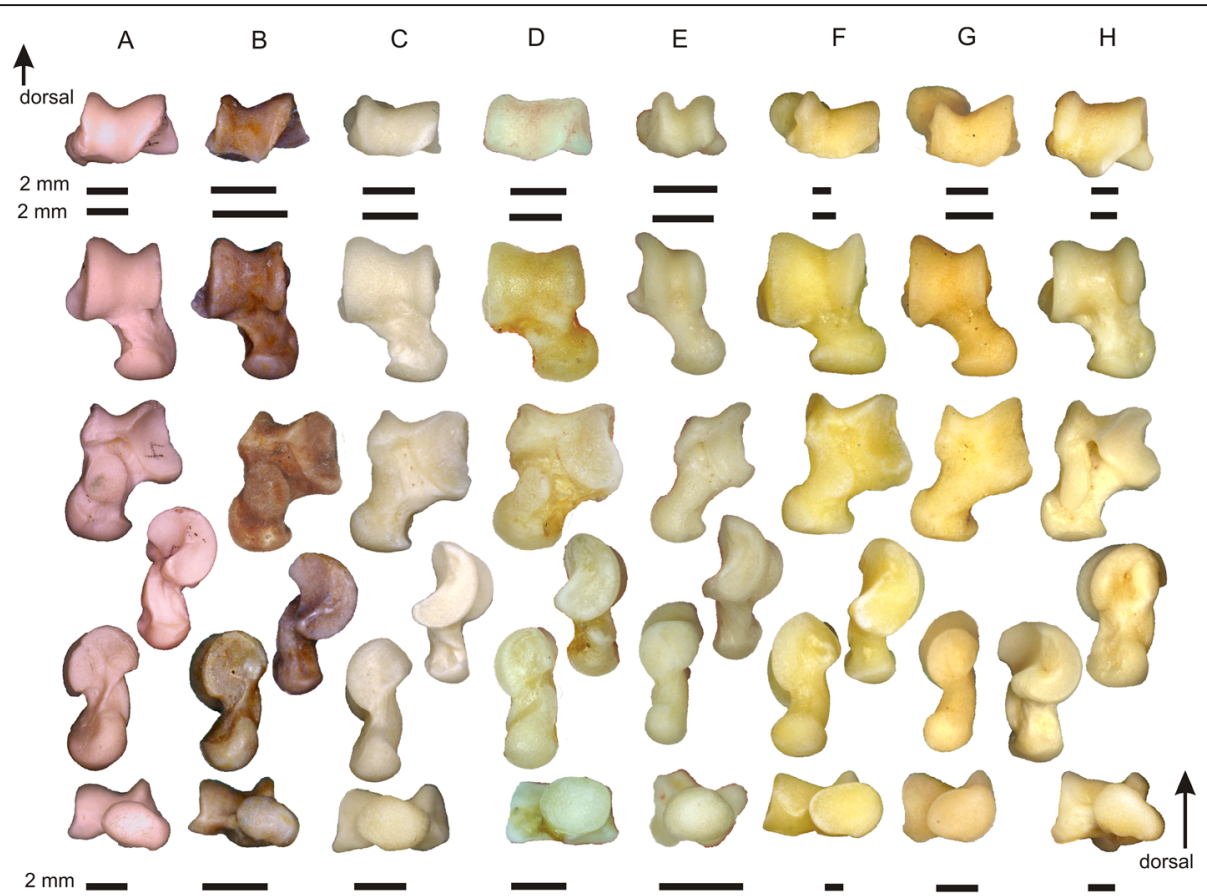

Fig. 6 Comparative morphology of the astragalus (right). Tamquammys robustus (a) IVPP V24136.4; (b) T. wilsoni, IVPP V24137.5 (mirror image); extant rodents: Rattus norvegicus (c), Cricetus cricetus (d), Glis glis (e), Marmota marmota (f), Sciurotamias davidianus (g), Ondatra zibethicus (h). Note a relatively deep trochlea and long erect neck, both indicators of improved orthal movement

astragalar neck, unlike in some basal primates where it is related to climbing adaptations [20], but ends at the trochlea-neck contact as in other rodents studied here (Fig. 6). The trochlea does not slope mediolaterally, unlike in Purgatorius (and other basal Euarchonta, see Chester et al. [20]: figs. 1 and 3), which supports at least limited cursorial adaptations in Tamquammys, and the absence of typical arboreal traits.

The neck of astragalus in Tamquammys is relatively erect and long, aligned closely to the sagittal axis of the bone, what can also be interpreted in favor of increased cursorial abilities, as such neck structure is typical of cursorially adapted rodents [12] and duplicidentates [25, 26]).

The astragalar head is strongly compressed dorsoventrally (but less than in paramyines and Purgatorius). In distal view the head is oval, slightly pear-shaped (wider laterally), and has a posteriorly extended articular facet for the navicular (Figs. 1 and 5), which encroaches onto the neck (higher than in most of the analyzed rodents except for Ondatra, and higher than in Tupaia), implying a great range of rotation in this joint, thus increased maneuverability of the foot. The astragalonavicular surface in Tamquammys is more convex than in Rattus, ground and rock squirrels, and Tupaia, although it is not as much bulged medially as in Purgatorius and plesiadapids.

The head is slightly rotated at the neck (ca. $20^{\circ}$ dorsally); a similar rotation is observed in Paramys (see Rose and Chinnery [17]: fig. 11c), Ondatra, and Gomphos, whereas in ground squirrels, Rattus, Tupaia (Fig. 5), and primates (e.g., Purgatorius and plesiadapids) the long axis of the head is oriented in mediolateral direction.

The astragalar ectal facet is subtriangular in outline (the wider side directed caudally) and concave. It is similar to that of Rattus and ground squirrels, but shallower than in Ondatra. The astragalar sustentacular facet is regularly oval (elongated craniocaudally). In Tamquammys robustus it is not fused or contacting the astragalonavicular facet (Figs. 1 and 6). In T. wilsoni the sustentacular facet is less defined posteriorly and somewhat extended towards the sustentacular hinge (Fig. $1 \mathrm{C} 1$ ), although it does not form a complete smooth extension onto this surface as it does in sciurids, paramyines [17], Ondatra, Tupaia, and in the plesiadapiform Dryomomys. Such extension is, however, absent in Purgatorius (see Chester et al. [20]: fig. 3d-e) and in Gomphos [24].

The astragalofibular facet at the medial wall of the medial crest of the astragalar trochlea is gently semicircular and concave (Figs. 1 and 6). The surface of the facet is upturned somewhat dorsally and has relatively larger area in both species of Tamquammys than that in Rattus and ground squirrels, resembling the facet of Ondatra, which is wider and more tightly curled (twisted). The facet serves as a strong support for the fibula, especially during the foot eversion, blocking the fibula from 'slipping' laterally or plantarly. Such dorsally 
upturned fibular surface is not present in typically cursorial animals (e.g., in lagomorphs [25]), but can be observed in Glis, which is an arboreal animal with good climbing ability. The facet is also not extended dorsally in Cynocephalus, Ptilocercus, and Tupaia, in contrast to that in Notharctus (Chester et al. [20]: fig. 3f) and some anthropoids [19]. The astragalofibular facet apparently serves as a temporary support for the fibula coming dynamically into action, especially during the foot eversion. It may allow stabilizing the crural joint during swift movements on uneven branches or terrain, when some additional ankle support is required. An upturned astragalofibular facet is lacking in Cynocephalus, because this animal employs a different mode of locomotion (crawling and claw climbing upon vertical substrates, or hanging beneath the branches). Given its big size, the colugo requires a weight bearing mechanism that would stabilize the foot, and the forces acting on the animal's limb bones are directed quite differently to these in e.g. Glis.

\section{Locomotor adaptations in Tamquammys}

The morphology of the astragalocalcaneal complex of Tamquammys does not indicate any prevailing locomotor adaptations, but rather suggests this animal was an agile terrestrial-scansorial generalist (Fig. 5).

The elongated, helical and not tightly curled ectal facet of the calcaneus, deep, posteriorly extended, tibial facet of the astragalus, relatively strong and large peroneal process, and extended astragalonavicular facet at the astragalus head indicate great mobility of the foot, especially its dorsoplantar flexibility at the crurotarsal joint [20]. Such potential for movement range is also indicated by a well developed and large sutentacular facet. Large (especially wide) sustentacula in rodents allow for greater freedom of movement along the astragalocalcaneal juncture and, according to Ginot et al. [12], are associated with increased climbing or aquatic adaptations, requiring foot to move effectively not simply in the parasagittal plane. The facilitation of sliding along the articular surfaces (e.g., not profoundly convex ectal facet) at the astragalocalcaneal contact points to efficient eversion-inversion of the foot [20]. This is especially true for the smaller species, Tamquammys wilsoni, although the extent of such foot rotation must have been much more limited in both species of Tamquammys than in typically arboreal taxa.

On the other hand, the structure of the crurotarsal surface reflected by a deep trochlea with straightly arranged ridges stabilizes the tibial insertion into the joint (protects against dislocations) and makes the joint more restricted in terms of the freedom of the mediolateral movements at the articulation surfaces, and can be regarded as cursorial adaptations (perfected e.g., in lagomorphs [25], but observed also in cursorial rodents
[12]). This morphological trait in the astragalocalcaneal complex of Tamquammys is also supported by the relative slenderness and somewhat elongated calcaneal body and relatively erect astragalar neck. The inclined calcaneonavicular surface of the calcaneus also prevents a large degree of rotation at this surface, thus the foot position is more stable.

The elongation of the calcaneal body in Euarchonta is correlated with an increase of the jumping ability [10], be it terrestrial leaping or arboreal vertical jumping (but see also Moyà-Solà et al. [28] for a different explanation); in the latter case the elongation of the calcaneal body can be brought to extreme as in e.g., Tarsius or Omomyidae $[19,20]$. The same regularity, although to a much lesser extent was reported also for Glires; e.g., in highly cursorial leporids [25] and some rodents (e.g., Ginot et al. [12]), indicating the proximal calcaneal elongation as one of the hallmarks of cursorial/or jumping Euarchontoglires. The relative elongation of the calcaneal body in Tamquammys indicates moderate jumping/bounding potential, probably better developed than in Rattus and Tupaia, but less in comparison to rock or ground squirrels (especially smaller genera, such as Sciurotamias and Cynomys), which display increased bounding.

Judging on the skeletal traits presented here and supported by paleoenvironmental data $[7,9,29]$ we propose Tamquammys as a forest floor dweller, occasionally climbing at the lower branches (Fig. 7), in search of food or escaping from predators, capable also of a swift run on uneven terrestrial substrate. The overall greater slenderness, longer helical ectal facet, and slightly longer calcaneal body in $T$. wilsoni suggest that it was more likely climbing trees or shrubs than larger $T$. robustus. The results of principal component analysis (Fig. 5; Additional file 1) of the astragalocalcaneal complex (especially of the calcaneus) support such interpretation, with Tamquammys robustus positioned in morphospace closer to Rattus and ground/rock squirrels (Cynomys and Sciurotamias), and Tamquammys wilsoni clustering with Purgatorius and Tupaia, showing basic arboreal adaptations (Fig. 5).

\section{Principal component analysis Calcaneus}

Results of principal component analysis include calcanei attributed to Tamquammys robustus plotting within generally cursorial to terrestial rock climbing species morphospace, which is distinctly separated from typical ground squirrels and large taxa including semiaquatic Ondatra (Fig. 5a). T. wilsoni plots closest to Glis glis and near unspecialized arboreal species morphospace. Principal component 1 (PC1) represents $96.6 \%$ of the variance. All variables show positive loading for PC1 (Additional 


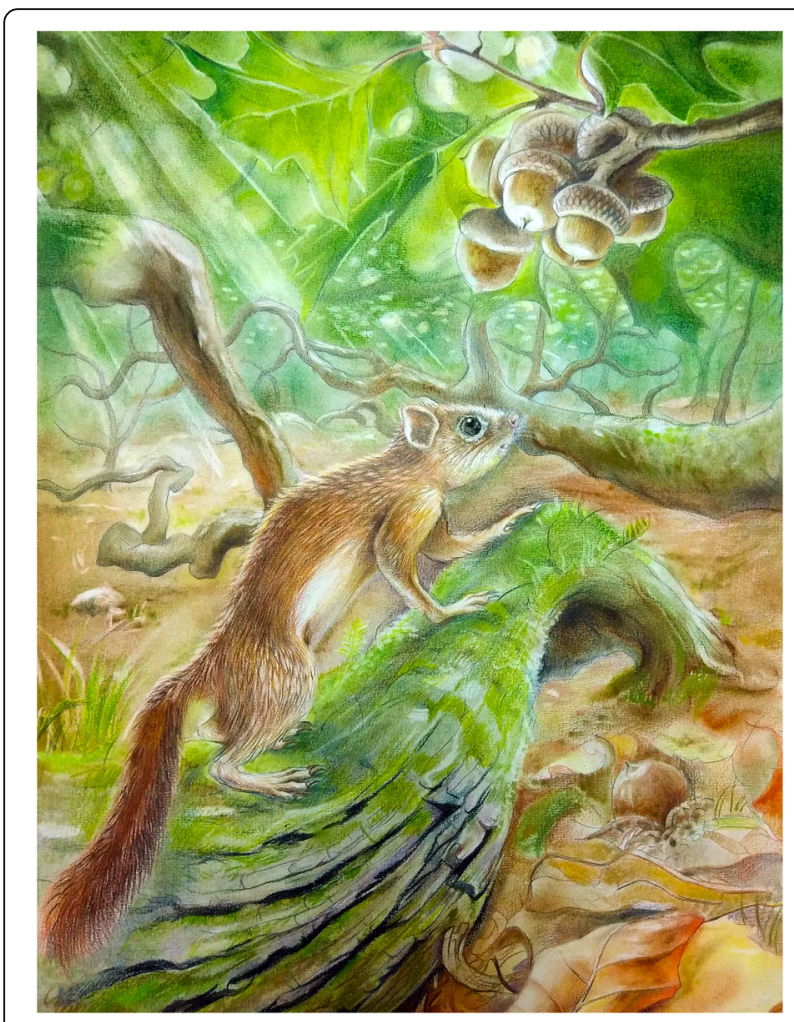

Fig. 7 Life reconstruction of Tamquammys robustus in a forest environment during the early Eocene (Arshantan) in the Erlian Basin (Nei Mongol, China). Hand drawing by Xiaocong Guo

file 1: Figure S4) and they are weakly positively correlated (0.22-0.32) with this component. Generally, a calcaneus with a high $\mathrm{PC} 1$ score has a longer proximodistal length. Low PC1 scores generally represent the opposite condition. PC2 represents $1.32 \%$ of the variance. It is most strongly, although moderately, correlated with variables Ca4 (- 0.46) and Ca5 (0.49). Generally, a calcaneus with a high PC2 score has a tuber with a narrow caudal extremity and is thicker dorsoplantarly. Low PC2 scores generally represent the opposite conditions.

\section{Astragalus}

Results of principal component analysis include astragali attributed to Tamquammys robustus plotting within terrestrial and rock climbing species morphospace, which is distinct from that of arboreal and semiaquatic species (Fig. 5b). T. wilsoni plots closest to unspecialized arboreal species. Principal component 1 (PC1) represents $96.37 \%$ of the variance. All variables show positive loading for PC1 (Additional file 1: Figure S5), and all are weakly positively correlated $(0.26-0.33)$ with this component. Generally, an astragalus with a high PC1 score is longer proximodistally. Low PC1 scores generally represent the opposite condition. PC2 represents $1.37 \%$ of the variance. It is strongly negatively correlated $(-0.73)$ with variable As4 and moderately positively correlated (0.49) with variable As8. Generally, an astragalus with a high PC2 score has a short astragalar neck and a longer medial crest. Low PC2 scores generally represent the opposite conditions.

Overall, principal component 1 (PC 1) can be viewed as primarily a measure of proximodistal length of the bones. We could explain its dominant contribution to the total variance by a general uniformity of the astragalocalcaneal morphology among studied taxa; thus a large influence of size even on standardized measurements (see Methods).

\section{Discussion}

Phylogenetic position of Tamquammys and the antiquity of ctenodactyloid rodents

The phylogenetic position of Tamquammys within Rodentia is very basal according to Vianey-Liaud and Marivaux [30]. It is in polytomy with a clade composed of (Tribosphenomys + Archetypomys) + Cocomys, with Ischyromyiformes considered as more derived. However, its exact relationships to other basal ctenodactyloids, such as Cocomys (or Euxmys) are ambiguous, as Tamquammys has been often proposed as more derived [3, 31-33].

In a broader phylogenetic context Tamquammys is close to the rodentiaform (sensu Wyss and Meng [34]) Tribosphenomys (Fig. 2), which is regarded therein as a basal member of Simplicidentata (see Meng and Wyss [35]). Whether Tribosphenomys and, more broadly, Alagomyidae are ancestral to rodents or represent a specialized offshoot of basal Glires, is a matter of debate. Nevertheless, comprehensive phylogenetic analyses point to the basal position of ctenodactyloids within Rodentia [30] and Tamquammyidae within ctenodactyloids (see Marivaux et al. [32]: fig. 4).

From a paleontological perspective early rodent phylogeny is complicated by the fact that the fossil record of the Asian ctenodactyloids (earliest Eocene, Bumbanian ALMA; $[3,4]$ is predated by the North American ischyromyids, in particular the reithroparamyine lineage, appearing already in the late Paleocene (early Clarkforkian NALMA; [36, 37], about one million years earlier than the earliest ctenodactyloid rodents). Which of the two rodent groups, ctenodactyloids or ischyromyids, represents the most basal rodents is a challenging question. Wible et al. ([33]: fig. 23) regarded paramyines as more basal than Ctenodactyloidea, and Meng and Wyss [38] suggested Acritoparamys and Paramys as stem rodents (but see Meng et al. [39]). In the current paper we follow the most recent phylogenetic analysis of Vianey-Liaud and Marivaux ([30]: fig. 7), which places ischyromyiform rodents as more nested than Tamquammys, thus pointing towards Ctenodactyloidea as the most ancient true rodent lineage. 
The astragalocalcaneal morphology in Tamquammys In search of rodent ancestral morphotype

Szalay [15], in a discussion on the rodent locomotor adaptations modeled the ancestral 'protorodent' morphotype on the North American Paramys, which at that time was undoubtedly the best known representative of early rodents. Accordingly, he suggested that the earliest rodents were adapted mostly arboreal (as proposed for Paramys already by Wood [40]), but had evolved from generally terrestrial 'protoplacentals'. Further analyses regarded paramyines as more generalized in their locomotion abilities, with a mixture of arboreal and terrestrial adaptations, also including facultative burrowing [17, 41, 42].

Tamquammys shares with Szalay's ([15]: table 2) 'protorodent' the lack of the calcaneofibular facet, a helical ectal facet, and a slightly ovoid (especially in T. wilsoni) and deep calcaneocuboid surface. Whether it exhibited the tibiofibular syndesmosis in the lower fibular joint is uncertain, although likely, as this feature was also present in Rhombomylus [39] and Paramys [17]. Moreover, Tamquammys probably had a tibial posterior process, which is indicated by an anteroposteriorly extension of the trochlear surface on the astragalus. Unlike Szalay's 'protorodent', Tamquammys has a relatively symmetrical astragalar trochlea and lesser mediolateral extension of the astragalar head, but the trochlea symmetry is a highly variable character in different paramyine genera according to Rose and Chinnery [17], and thus of little value for phylogenetic inference. On balance, the astragalocalcaneal complex of Tamquammys apparently exhibits a more ancestral morphotype for the rodents than that of paramyines.

The morphology of the astragalocalcaneal complex of Tamquammys reveals more traits in common with the earliest Rodentiaformes (e.g. Tribosphenomys) and even more archaic groups of early-to-middle Paleocene Glires $[6,35,43,44]$ as well as Purgatorius than between the Rodentiaformes and Paramyines (see also Fig. 5).

Further, the structure of the astragalocalcaneal complex in Tamquammys displays some plesiomorphic features regarded by Szalay and Decker [21] as ancestral for early Paleocene Eutheria (exemplified therein by Protoungulatum, Procerberus, and Plesiadapis). These features are: an oblique calcaneocuboid facet, the ectal facet positioned askew (inclined $35-40^{\circ}$ to the long axis of the bone), the presence of the anterior plantar tubercle, the separate astragalar sustentacular facet, and a wide astragalar head, laterally thicker and rotated slightly dorsolaterally. Incidentally, most of these traits are poorly manifested in the late Cretaceous placental Zalambdalestes, which was regarded by Kielan-Jaworowska [45] as quite specialized. Apart from the above mentioned plesiomorphies,
Tamquammys displays several important derived characters, such as some elongation of the calcaneal body, a deep, straight-ridged, and relatively long astragalar trochlea, the peroneal process midway down the calcaneocuboid junction and the sustentaculum tali; additionally the astragalus lacks an astragalar canal. The rotation axis at the astragalocalcaneal articulation is oblique (another primitive character of Szalay and Decker [21], same as in most rodents, but this obliquity is nonetheless lesser than in the early Paleocene Eutheria studied by Szalay and Decker [21]).

The question of the ancestral condition of the tarsal joint and locomotor adaptations in the earliest Glires remains open (given the uncertain adaptations in Tribosphenomys; Fig. 5), although the morphology of the astragalocalcaneal complex in Tamquammys suggests terrestriality, not arboreality, as a point of departure for Glires. Furthermore, Tamquammys groups rather close in the morphospace with the basal primate Purgatorius (Fig. 5), and in the latter the arboreal adaptations in the astragalocalcaneal complex are relatively weakly expressed. This may suggest that a more generalized foot structure was indeed characteristic of early Euarchontoglires. Beginning with the early middle Eocene, we observe the increased variety of tarsal modifications in Rodentia, which in part contributed to the evolutionary success of the order, which continues up to modern times.

\section{Conclusions}

Tamquammys is one of the earliest ctenodactyloid rodents known from the early Paleogene of Asia. Its astragalocalcaneal morphology and locomotor adaptations are analyzed here against a broader background of major rodent morphotypes. The crurotarsal joint shows great mobility in the parasagittal plane and some limitations in mediolateral direction, which suggests general cursorial/terrestrial specialization, especially well expressed in a larger species ( $T$. robustus). The calcaneocuboid articular surface is markedly inclined, which also limits its mobility and points to a general cursorial specialization. T. wilsoni shows a better jumping ability indicated e.g., by a longer calcaneal body. The PCA analysis places $T$. robustus within terrestrial and rock climber species morphospace, whereas $T$. wilsoni clusters with unspecialized arboreal rodent species such as Glis glis, tupaiid scandentians, and Purgatorius, a putative 'proto-primate'. Because the morphology of the astragalocalcaneal ensemble of Tamquammys does not depart far from that of the early Paleocene Purgatorius, our findings contribute to establishing the original 'paleorodent' morphotype as close to basal Euarchonta. 


\section{Methods \\ Material}

The tarsal bones of Tamquammys robustus come from the lower Arshantan (AS-1) of Nuhetingboerhe, whereas those of $T$. wilsoni come from both the Arshantan and Irdinmanhan (IM-1) strata of Nuhetingboerhe and Huheboerhe. Both localities are in the eastern part of the Erlian Basin, Nei Mongol, China (see Wang et al. $[9,46]$ for details). We have allocated the tarsal bones to respective Tamquammys species on the basis of dental remains accompanying the bones in the same localities. In the sediment beds of the lower Arshanto Formation Tamquammys is the only known rodent, represented by two species ( $T$. robustus and $T$. wilsoni). The morphology of the bones from the Irdin Manha Formation assigned to T. wilsoni is consistent with that of the tarsal bones of the same species yielded by the Arshantan strata. Mass estimate for both species are provided in Fostowicz-Frelik et al. ([26]: table S6). Comparative material comprises 10 extant and 2 fossil rodent species, one rodentiaform, 2 duplicidentate taxa, and 2 basal Euarchontoglires representing main ecomorphs (generalist, arboreal and rock climbers, fossorial, semiaquatic, ambulatory, and cursorial), and is listed in Additional file 1 (Table S1). All Tamquammys specimens are deposited in the collection of the Institute of Vertebrate Paleontology and Paleoanthropology of Chinese Academy of Sciences, Beijing (abbreviated IVPP).

\section{Measurements}

We took 15 linear measurements on the calcaneus of 36 specimens and 12 linear measurements on the astragalus of 25 specimens; measurements are provided in Additional file 1: Tables S4-5. We analyzed quantitative data using JMP 8 (SAS Institute Inc.). To estimate the interspecific differences, we used boxplots (Additional file 1: Figures S2-S3); each boxplot displays the 10th, 25th, the median, 75th and 90th percentiles of variable.

\section{Principal component analysis}

To assess our qualitative observations we run principal component analysis on the variance-covariance matrix using the singular value decomposition (SVD) algorithm. PCA analyses were conducted using PAST v. 2.17 [47]. Before running PCA we size-standardized linear measurements using the geometric mean transformation of the data following Mosimann and James [48]. To measure suitability of our data for PCA we used a Kaiser-Meyer-Olkin (KMO) Test for Sampling Adequacy (see Additional file 1: Table S6) implemented in Factor Analysis v. 10.8.03 (U. Lorenza Seva \& P.J. Ferrando, Universitat Rovira i Virgili, Tarragona, Spain). For eigenvalue, component loadings and percentage variance for each principal component, see Additional file 1: Table S7.

\section{Terminology and abbreviations}

The terminology of tarsal elements follows Gladman et al. [19] with some modifications from Evans [49] and Szalay [15]. The measurements and anatomical terms used in the paper are provided in Additional file 1: Figure S1 and listed on Tables S2-S3.

\section{Additional file}

Additional file 1: Table S1. Specimens examined in morphological analyses. Table S2. Guide to the bone measurements - calcaneus. Table S3. Guide to the bone measurements - astragalus. Figure S1. Measurements of the tarsal elements shown at the right calcaneus (A, B) and right astragalus (C, D) of Tamquammys robustus (IVPP coll. V24136.1 and IVPP coll. V24136.4, respectively) from the Arshanto Formation (early Eocene) of Nuhetingboerhe section, Erlian Basin, Nei Mongol, China. Figure S2. Ratios for calcaneal measurements. A, slenderness ratio (CW/ $\mathrm{CL}) ; \mathrm{B}$, calcaneal load arm (CBL/CL); C tuber proportions (TCW/TCdp); D, relative length of the ectal facet $(C E L / C L)$; $E$, proportions of the calcaneocuboid facet (CaCuW/CaCuL). Abbreviations: A.te, Arvicola terrestris; C.cr, Cricetus cricetus; C.lud, Cynomys ludovicianus; G.gl, Glis glis; G.el, Gomphos elkema; M.ma, Marmota marmota; M.mu, Mus musculus; O.pa, Ochotona pallasi; O.zi, Ondatra zibethicus; Par., paramyine rodent; Pur, Purgatorius; R.no, Rattus norvegicus; S.vu, Sciurus vulgaris; T.gl, Tupaia glis; T.mi, Tribosphenomys minutus; T.ro, Tamquammys robustus; T.wi, Tamquammys wilsoni. Colors: red for rodents; yellow for Rodentiaformes; green for stem duplicidentate and lagomorph; blue for Euarchonta (basal primate and Scandentia). Figure S3. Ratios for astragalar measurements. $A$, trochlear ratio (TW/AL); $B$, neck ratio $(\mathrm{NL} / \mathrm{AL})$ ); $\mathrm{C}$ head proportions $(\mathrm{HW} /$ $\mathrm{NL})$; D, trochlear crests ratio (MCL/LCL); abbreviations as in Figure S2. Table S4. Measurements of calcaneus of Tamquammys robustus, $T$. wilsoni, and comparative taxa (in $\mathrm{mm}$ ). Table S5. Measurements of astragalus of Tamquammys robustus and T. wilsoni and comparative taxa (in $\mathrm{mm}$ ). Table S6. Results of Kaiser-Meyer-Olkin (KMO) Test for sampling adequacy. Table S7. Eigenvalues for calcaneus (A) and astragalus (B) PCA analysis. Figure S4. PCA loadings for the calcaneus. Loadings are for variables described in Table S2 (Ca1-15). Figure S5. PCA loadings for t he astragalus. Loadings are for variables described in Table S3 (As1-12). (DOCX $1745 \mathrm{~kb})$

\section{Acknowledgements}

We thank Jin Meng, Yuanqing Wang, Bin Bai, Xun Jin, Ping Li, K. C. Beard, D. L. Gebo, Wei Chen, Wei Zhou, Shejie Li, Qiang Cao, Wei Gao, Chenkai Sun, and Qi Li for their assistance during fieldwork. We are grateful to Xiaocong Guo for expertly preparing Fig. 7. We thank Barbara Miękina for access to comparative material. Joshua X. Samuels and an anonymous reviewer offered very helpful comments on earlier versions of the paper.

\section{Funding}

The present work was supported by the National Science Centre (Cracow, Poland) grant No. 2015/18/E/NZ8/00637 to ŁFF, the National Natural Science Foundation of China (grant No. 41572013), and the Strategic Priority Research Program of the Chinese Academy of Sciences (XDPB05). The fieldwork was also supported by the Special Fund for Fossil Excavation and Preparation, Chinese Academy of Sciences.

\section{Availability of data and materials}

The data generated or analyzed during this study are included in this published article [and its additional files].

\section{Authors' contributions}

ŁFF designed and originated the study. All authors participated in acquisition, analysis and interpretation of data. All authors read and approved the final manuscript. 


\section{Ethics approval and consent to participate}

Not applicable.

\section{Consent for publication}

Not applicable.

\section{Competing interests}

The authors declare that they have no competing interests.

\section{Publisher's Note}

Springer Nature remains neutral with regard to jurisdictional claims in published maps and institutional affiliations.

\section{Received: 8 November 2017 Accepted: 10 September 2018} Published online: 04 October 2018

\section{References}

1. Shevyreva NS. The first find of Eocene rodents in the USSR. Bull Acad Sci Georg SSR. 1971;61:745-7.

2. Dawson MR, Li CK, Qi T. Eocene ctenodactyloid rodents (Mammalia) of eastern Central Asia. Carnegie Mus Nat Hist Spec Pub. 1984:9:138-50.

3. Li Q, Meng J. New ctenodactyloid rodents from the Erlian Basin, Nei Mongol, China, and the phylogenetic relationships of Eocene Asian ctenodactyloids. Am Mus Novit. 2015;3828:1-58.

4. Li Q. Eocene fossil rodent assemblages from the Erlian Basin (Inner Mongolia, China): biochronological implications. Palaeoworld. 2016;25:95103.

5. Tong YS. Middle Eocene small mammals from Liguanqiao Basin of Henan Province and Yuanqu Basin of Shanxi Province, Central China. Paleontol Sin 18 New Ser. 1997:C26:1-256.

6. Dashzeveg D, Russell DE. Palaeocene and Eocene Mixodontia (Glires) of Mongolia and China. Palaeontology. 1988;31:129-64.

7. Meng J, Ni XJ, Li CK, Beard KC, Gebo D, Wang YQ. New material of Alagomyidae (Mammalia, Glires) from the late Paleocene Subeng locality, Inner Mongolia. Am Mus Novit. 2007;3597:1-29.

8. Meng J, Li CK. New rodents from the earliest Eocene of Nei Mongol, China. Vertebrat PalAsiatic. 2010;48:390-401.

9. Wang YQ, Meng J, Beard KC, Li Q, Ni XJ, et al. Early Paleogene stratigraphic sequences, mammalian evolution and its response to environmental changes in Erlian Basin, Inner Mongolia, China. Sci China Ser D. 2010;53:1918-26.

10. Boyer DM, Seiffert ER, Gladman JT, Bloch Jl. Evolution and allometry of calcaneal elongation in living and extinct Primates. PLoS One. 2013;8:e67792

11. Candela AM, Muñoz NA, García-Esponda CM. The tarsal-metatarsal complex of caviomorph rodents: anatomy and functional-adaptive analysis. J Morph. 2017:278:828-47.

12. Ginot S, Hautier L, Marivaux L, Vianey-Liaud M. Ecomorphological analysis of the astragalo-calcaneal complex in rodents and inferences of locomotor behaviours in extinct rodent species. PeerJ. 2016;4:e2393.

13. Decker RL, Szalay FS. Origins and function of the pes in the Eocene Adapidae (Lemuriformes, Primates). In: Jenkins FA, editor. Primate locomotion. New York: Academic Press; 1974. p. 261-91.

14. Gebo DL, Dagosto M, Beard KC, Qi T. Middle Eocene primate tarsals from China: implications for Haplorhine evolution. Am J Phys Anthropol. 2001; 116:83-107.

15. Szalay FS. Rodent and lagomorph morphotype adaptations, origins, and relationships: some postcranial attributes analyzed. In: Luckett WP, Hartenberger $\mathrm{L}$, editors. Evolutionary relationships among rodents. A multidisciplinary analysis. New York: Plenum Press; 1985. p. 83-132.

16. Averianov AO. Tarsals of Glires (Mammalia) from the early Eocene of Kirgizia. Geobios. 1991;24:215-20

17. Rose KD, Chinnery BJ. The postcranial skeleton of early rodents. Bull Carnegie Mus Nat Hist. 2004;36:211-44.

18. Romankowowa A. Comparative study of the structure of the os calcaneum in insectivores and rodents. Acta Theriol. 1963;7:91-126.

19. Gladman JT, Boyer DM, Simons EL, Seiffert ER. A calcaneus attributable to the primitive late Eocene anthropoid Proteopithecus sylviae: phenetic affinities and phylogenetic implications. Am J Phys Anthropol. 2013;151:372-97.
20. Chester SB, Bloch JI, Boyer DM, Clemens WA. Oldest known euarchontan tarsals and affinities of Paleocene Purgatorius to Primates. P Natl Acad Sci USA. 2015;112:1487-92.

21. Szalay FS, Decker RL. Origins, evolution, and function of the tarsus in late cretaceous Eutheria and Paleocene Primates. In: Jenkins FA, editor. Primate locomotion. New York: Academic Press; 1974. p. 223-59.

22. Bleefeld AR, Bock WJ. Unique anatomy of lagomorph calcaneus. Acta Palaeontol Pol. 2002:47:181-3.

23. Zhang ZQ, Li CK, Wang J, Wang YQ, Meng J. Presence of the calcaneal canal in basal Glires. Vertebrat PalAsiatic. 2016;54:235-42.

24. Meng J, et al. Gomphos elkema (Glires, Mammalia) from the Erlian Basin: evidence for the early tertiary Bumbanian land mammal age in Nei-Mongol, China. Am Mus Novit. 2004:3425:1-24

25. Fostowicz-Frelik $Ł$. The hind limb skeleton and cursorial adaptations of the Plio-Pleistocene rabbit Hypolagus beremendensis. Acta Palaeontol Pol. 2007;52:447-76

26. Fostowicz-Frelik $Ł$, Li CK, Mao F, Meng J, Wang YQ. A large mimotonid from the middle Eocene of China sheds light on the evolution of lagomorphs and their kin. Sci Rep. 2015:5:9394.

27. Fostowicz-Frelik Ł. Convergent and parallel evolution in early Glires (Mammalia). In: Pontarotti P, editor. Evolutionary biology: self/nonself evolution, species and complex traits evolution, methods and concepts. Cham: Springer; 2017. p. 199-216.

28. Moyà-Solà S, Köhler M, Alba DM, Roig I. Calcaneal proportions in primates and locomotor inferences in Anchomomys and other Paleogene Euprimates. Swiss J Palaeontol. 2012;131:147-59.

29. Jenkins FA. Tree shrew locomotion and the origins of primate arborealism. In: Jenkins FA, editor. Primate locomotion. New York: Academic Press; 1974. p. $85-115$.

30. Vianey-Liaud M, Marivaux L. Autopsie d'une radiation adaptative: Phylogénie des Theridomorpha, rongeurs endémiques du Paléogène d'Europe histoire, dynamique évolutive et intérêt biochronologique. Palaeovertebrata. 2016;40:e1; https://doi.org/10.18563/pv.40.4.01

31. Dashzeveg D, Meng J. New Eocene ctenodactyloid rodents from the eastern Gobi Desert of Mongolia and a phylogenetic analysis of ctenodactyloids based on dental features. Am Mus Novit. 1998:3246:1-20.

32. Marivaux L, Vianey-Liaud M, Jaeger JJ. High-level phylogeny of early tertiary rodents: dental evidence. Zool J Linnean Soc. 2004;142:105-34.

33. Wible JR, Wang YQ, Li CK, Dawson MR. Cranial anatomy and relationships of a new ctenodactyloid (Mammalia, Rodentia) from the early Eocene of Hubei Province, China. Ann Carnegie Mus. 2005;74:91-150.

34. Wyss AR, Meng J. Application of phylogenetic taxonomy to poorly resolved crown clades: a stem-modified node-based definition of Rodentia. Syst Biol. 1996:45:559-68.

35. Meng J, Wyss AR. The morphology of Tribosphenomys (Rodentiaformes, Mammalia): phylogenetic implications for basal Glires. J Mamm Evol. 2001:8:1-71

36. Dawson MR, Beard KC. New late Paleocene rodents (Mammalia) from Big Multi Quarry, Washakie Basin, Wyoming. Palaeovertebrata. 1996:25:301-21.

37. Anderson D. Ischyromyidae. In: Janis CM, Gunnell GF, Uhen MD, editors. Evolution of tertiary mammals in North America. Volume 2: small mammals, xenarthrans, and marine mammals. Cambridge: Cambridge University Press; 2008. p. $311-25$.

38. Meng J, Wyss AR. Glires (Lagomorpha, Rodentia). In: Rose KD, Archibald JD, editors. The rise of placental mammals. Baltimore: The Johns Hopkins University Press; 2005. p. 145-58

39. Meng J, Hu Y, Li CK. The osteology of Rhombomylus (Mammalia, Glires): implications for phylogeny and evolution of Glires. Bull Am Mus Nat Hist. 2003:275:1-248

40. Wood AE. The early tertiary rodents of the family Paramyidae. T Am Philos Soc New Ser. 1962:52:1-261.

41. Emry RJ, Thorington RW. Descriptive and comparative osteology of the oldest fossil squirrel, Protosciurus (Rodentia: Sciuridae). Smithsonian Contrib Paleobiol. 1982:(47):1-35.

42. Bertrand OC, Schillaci MA, Silcox MT. Cranial dimensions as estimators of body mass and locomotor habits in extant and fossil rodents. J Vert Paleontol. 2015. https://doi.org/10.1080/02724634.2015.1014905.

43. Sych L. Mixodontia, a new order of Mammalia from the Paleocene of Mongolia. Palaeontol Pol. 1971;25:147-58.

44. Li CK. Paleocene eurymyloids (Anagalida, Mammalia) of Qianshan, Anhui. Vertebrat PalAsiatic. 1977;15:103-20. 
45. Kielan-Jaworowska Z. Evolution of the therian mammals in the late cretaceous of Asia. Part III. Postcranial skeleton in Zalambdalestidae. Palaeontol Pol. 1978;38:5-41.

46. Wang YQ, Meng J, Jin X. Comments on Paleogene localities and stratigraphy in the Erlian Basin, Nei Mongol, China. Vertebrat PalAsiatic. 2012:50:181-203.

47. Hammer $\varnothing$, Harper DAT, Ryan PD. PAST: paleontological statistics software package for education and data analysis. Palaeontol Electron. 2001;4(1):1-9.

48. Mosimann JE, James FC. New statistical methods for allometry with application to Florida red-winged blackbirds. Evolution. 1979;33(1):444-59.

49. Evans HE. Miller's anatomy of the dog. 3rd ed. Philadelphia: Saunders; 1993.

Ready to submit your research? Choose BMC and benefit from:

- fast, convenient online submission

- thorough peer review by experienced researchers in your field

- rapid publication on acceptance

- support for research data, including large and complex data types

- gold Open Access which fosters wider collaboration and increased citations

- maximum visibility for your research: over $100 \mathrm{M}$ website views per year

At $\mathrm{BMC}$, research is always in progress.

Learn more biomedcentral.com/submissions 